\title{
Non-invasive assessment of respiratory muscle activity during pressure support ventilation: accuracy of end-inspiration occlusion and least square fitting methods
}

\author{
Giuseppe Natalini ${ }^{1} \cdot$ Barbara Buizza $^{2} \cdot$ Anna Granato $^{1,3} \cdot$ Eros Aniballi $^{1,3} \cdot$ Luigi Pisani $^{1,5} \cdot$ Gianni Ciabatti $^{7}$. \\ Valeria Lippolis $^{1,4}$. Antonio Rosano ${ }^{1}$. Nicola Latronico ${ }^{2,8}$. Salvatore Grasso ${ }^{4}$. Massimo Antonelli ${ }^{3,6}$. \\ Achille Bernardini ${ }^{1}$
}

Received: 22 January 2020 / Accepted: 26 June 2020 / Published online: 2 July 2020

(c) Springer Nature B.V. 2020

\begin{abstract}
Pressure support ventilation (PSV) should be titrated considering the pressure developed by the respiratory muscles $\left(\mathrm{P}_{\text {musc }}\right)$ to prevent under- and over-assistance. The esophageal pressure $\left(\mathrm{P}_{\mathrm{es}}\right)$ is the clinical gold standard for $\mathrm{P}_{\text {musc }}$ assessment, but its use is limited by alleged invasiveness and complexity. The least square fitting method and the end-inspiratory occlusion method have been proposed as non-invasive alternatives for $\mathrm{P}_{\text {musc }}$ assessment. The aims of this study were: (1) to compare the accuracy of $\mathrm{P}_{\text {musc }}$ estimation using the end-inspiration occlusion $\left(\mathrm{P}_{\text {musc,index }}\right)$ and the least square fitting $\left(\mathrm{P}_{\text {musc,lsf }}\right)$ against the reference method based on $\mathrm{P}_{\mathrm{es}}$; (2) to test the accuracy of $P_{\text {musc,lsf }}$ and of $\mathrm{P}_{\text {musc,index }}$ to detect overassistance, defined as $\mathrm{P}_{\text {musc }} \leq 1 \mathrm{cmH}_{2} \mathrm{O}$. We studied 18 patients at three different PSV levels. At each PSV level, $\mathrm{P}_{\text {musc }}, \mathrm{P}_{\text {musc,lsf }}, \mathrm{P}_{\text {musc,index }}$ were calculated on the same breaths. Differences among $\mathrm{P}_{\text {musc }}, \mathrm{P}_{\text {musc,lsf }}, \mathrm{P}_{\text {musc,index }}$ were analyzed with linear mixed effects models. Bias and agreement were assessed by Bland-Altman analysis for repeated measures. The ability of $\mathrm{P}_{\text {musc,lsf }}$ and $\mathrm{P}_{\text {musc,index }}$ to detect overassistance was assessed by the area under the receiver operating characteristics curve. Positive and negative predictive values were calculated using cutoff values that maximized the sum of sensitivity and specificity. At each PSV level, $P_{\text {musc,lsf }}$ was not different from $P_{\text {musc }}(p=0.96)$, whereas $P_{\text {musc,index }}$ was significantly lower than $P_{\text {musc }}$. The bias between $\mathrm{P}_{\text {musc }}$ and $\mathrm{P}_{\text {musc,lsf }}$ was zero, whereas $\mathrm{P}_{\text {musc,index }}$ systematically underestimated $\mathrm{P}_{\text {musc }}$ of $6 \mathrm{cmH}_{2} \mathrm{O}$. The limits of agreement between $\mathrm{P}_{\text {musc }}$ and $\mathrm{P}_{\text {musc,lsf }}$ and between $\mathrm{P}_{\text {musc }}$ and $\mathrm{P}_{\text {musc,index }}$ were $\pm 12 \mathrm{cmH}_{2} \mathrm{O}$ across bias. Both $\mathrm{P}_{\text {musc,lsf }} \leq 4 \mathrm{cmH}_{2} \mathrm{O}$ and $\mathrm{P}_{\text {musc,index }} \leq 1 \mathrm{cmH}_{2} \mathrm{O}$ had excellent negative predictive value [0.98 (95\% CI 0.94-1) and 0.96 (95\% CI 0.91-0.99), respectively)] to identify over-assistance. The inspiratory effort during PSV could not be accurately estimated by the least square fitting or end-inspiratory occlusion method because the limits of agreement were far above the signal size. These non-invasive approaches, however, could be used to screen patients at risk for absent or minimal respiratory muscles activation to prevent the ventilator-induced diaphragmatic dysfunction.
\end{abstract}

Keywords Mechanical ventilation · Inspiratory effort · Respiratory muscles $\cdot$ Esophageal pressure $\cdot$ Least square fitting · End-inspiratory occlusion

\section{Abbreviations}

CI Confidence interval

$\mathrm{E}_{\mathrm{cw}} \quad$ Chest wall elastance

$\mathrm{E}_{\mathrm{rs}} \quad$ Elastance of the respiratory system

$\mathrm{P}_{0} \quad$ Basal pressure

$\mathrm{P}_{0.1} \quad$ Airway occlusion pressure at $100 \mathrm{~ms}$

Achille Bernardini: Deceased.

Gianni Ciabatti

ciabs@hotmail.it

Extended author information available on the last page of the article
$\mathrm{P}_{\text {appl }}$

$\mathrm{P}_{\mathrm{aw}}$

$\mathrm{P}_{\mathrm{cW}}$

$\mathrm{P}_{\mathrm{el}}$

$\mathrm{P}_{\text {exp,es }}$

$\mathrm{P}_{\text {musc }}$

$\mathrm{P}_{\text {musc,index }}$

$\mathrm{P}_{\text {musc,lsf }}$

$\mathrm{P}_{\text {plat,aw }}$
Pressure applied to the respiratory system Airway pressure

Relaxation pressure of the chest wall

Elastic pressure

End-expiratory plateau esophageal pressure

Pressure developed by respiratory muscles during inspiration

$\mathrm{P}_{\text {musc }}$ estimated by the end-inspiration occlusion method

$\mathrm{P}_{\text {musc }}$ estimated by the least square fitting method

End-inspiratory plateau airway pressure 


$\begin{array}{ll}\mathrm{P}_{\text {plates }} & \text { End-inspiratory plateau esophageal pressure } \\ \mathrm{P}_{\text {res }} & \text { Resistive pressure } \\ \text { PEEP } & \text { Positive end-expiratory pressure } \\ \text { PEEP }_{\text {tot }} & \text { Total PEEP } \\ \text { PS } & \text { Pressure support } \\ \text { PS }_{\text {base }} & \text { Baseline PS } \\ \text { PS }_{\text {max }} & \text { Maximal PS } \\ \text { PS }_{\min } & \text { Minimal PS } \\ \text { PSV } & \text { Pressure support ventilation } \\ \text { PTP } & \text { Pressure-time product } \\ \mathrm{R}_{\mathrm{rs}} & \text { Resistance of the respiratory system } \\ \text { ROC } & \text { Receiver operating characteristics } \\ \mathrm{V} & \text { Volume } \\ \mathrm{V}^{\prime} & \text { Flow }\end{array}$

\section{Background}

Pressure support ventilation (PSV) is a ventilatory mode that supports the pressure developed by respiratory muscles during inspiration $\left(\mathrm{P}_{\text {musc }}\right)$ with an external positive pressure applied at the airway opening, synchronized with the inspiratory effort. Since PSV supports the spontaneous breathing effort it should be titrated on patient's instantaneous $P_{\text {musc }}$ to prevent under- and over-assistance, i.e. PSV-induced respiratory muscle fatigue and atrophy, respectively [1]. Unfortunately, since $\mathrm{P}_{\text {musc }}$ is not easily measured in clinical practice, the degree of support is in fact titrated taking into account the overall clinical appearance of the patient, few breathing pattern parameters as respiratory rate and tidal volume, and, finally the airway pressure $\left(\mathrm{P}_{\mathrm{aw}}\right)$ and airflow waveforms on the ventilator screen.

The esophageal pressure method is the clinical gold standard for $\mathrm{P}_{\text {musc }}$ assessment [2], but it is seldom used in daily practice due its alleged invasiveness and complexity. The least square fitting [3] and the end-inspiratory occlusion methods [4] have been proposed as non-invasive alternatives. The least square fitting is the instantaneous computation of $\mathrm{P}_{\text {musc }}$ derived by solving the equation of motion [5] by $\mathrm{P}_{\mathrm{aw}}$, airflow, inspired volume, respiratory system elastance and resistance $\left(\mathrm{E}_{\mathrm{rs}}\right.$ and $\mathrm{R}_{\mathrm{rs}}$, respectively) [3]. The end-inspiration occlusion method estimates the end-inspiratory $\mathrm{P}_{\text {musc }}$ as the difference between the $\mathrm{P}_{\text {aw }}$ applied by the ventilator during the inspiratory phase $\mathrm{P}_{\mathrm{aw}}$ and the plateau reached by $\mathrm{P}_{\mathrm{aw}}$ during an end-inspiratory airway occlusion maneuver [4]. Both these methods have been evaluated in physiological studies, conducted on relatively few patients $[3,4]$ but to our knowledge their validation against the "reference" $\mathrm{P}_{\mathrm{es}}$ method is lacking. Thus, it is not clear whether they are sufficiently accurate to guide PSV titration in clinical practice.

The primary aim of this study was to compare $\mathrm{P}_{\text {musc }}$ calculated from $\mathrm{P}_{\mathrm{es}}$ with its estimation by the end-inspiration occlusion method $\left(\mathrm{P}_{\text {musc,index }}\right)$ and by the least square fitting method $\left(\mathrm{P}_{\text {musc.lsf }}\right)$ in critically ill patients ventilated with the PSV mode. The secondary aim was to test the accuracy of $\mathrm{P}_{\text {musc,lsf }}$ and $\mathrm{P}_{\text {musc,index }}$ to detect overassistance during PSV, defined as a near-passive patients $\left(\mathrm{P}_{\text {musc }} \leq 1 \mathrm{cmH}_{2} \mathrm{O}\right)$.

\section{Methods}

\subsection{Patients}

Consecutive patients were recruited in the Intensive Care Unit of Poliambulanza Foundation Hospital (Brescia, Italy) between January 2016 and June 2016. Inclusion criteria were: age $>18$ years; dependence on invasive mechanical ventilation (i.e. not ready to be weaned or having failed a spontaneous breathing trial on the day of the study [6]); PSV used as ventilatory mode; absence of flow limitation as assessed by maneuver of compression of the abdomen [7-9]. Patients were excluded in case of: hemodynamic instability (defined as mean arterial pressure $<60 \mathrm{mmHg}$, systolic arterial pressure $>180 \mathrm{mmHg}$, heart rate $<40$ / min or $>150 / \mathrm{min}) ; \mathrm{PaO}_{2} / \mathrm{FIO}_{2}<150 \mathrm{mmHg} ; \mathrm{pH}<7.35$ with $\mathrm{PaCO}_{2}>45 \mathrm{mmHg}$; contraindication to perform the maneuver of compression of the abdomen [7]; diagnosis of head injury, intracranial hemorrhage or cerebral ischemia. The protocol was approved by the local ethical committee (Comitato Etico Provinciale di Brescia, approval number NP2245). Written informed consent was obtained from the patient. In case of altered consciousness, the Ethics Committees waived the requirement for consent, as in Italy relatives are not regarded as legal representatives of the patient in the absence of a formal designation. Written informed consent was requested from all surviving patients as soon as they regained their mental competency. All investigations were conducted according to the principles expressed in the Declaration of Helsinki.

Esophageal pressure was measured by an esophageal balloon catheter (Marquat Gbm, Boissy-St-Léger Cedex, France) connected to a pressure transducer (AS3/CS3; Datex-Engstrom Division, Instrumentarium Corp., Helsinki, Finland). The esophageal balloon was introduced $40 \mathrm{~cm}$ from the nostril and inflated with $1 \mathrm{ml}$ of air. The occlusion test was used to assess if the esophageal pressure was appropriately transduced [10]. The position of the balloon in the esophagus and its filling volume were optimized to obtain a ratio between esophageal and airway pressure swings during occlusion ranging between 0.8 and $1.2[11,12]$.

\subsection{Study protocol}

The clinical PSV level at the patient's enrollment was defined as baseline PSV $\left(\mathrm{PS}_{\text {base }}\right)$. Successively, in order to explore a wide clinical range of PS assistance, maximal and 
minimal PS (PS $\mathrm{Pax}_{\max }$ and $\mathrm{PS}_{\min }$, respectively) were titrated as follows: $\mathrm{PS}_{\max }$ was sought by progressively increasing the PS until disappearance of any sign of inspiratory muscle activity after inspiratory triggering. This was assessed by visual inspection of the $\mathrm{P}_{\mathrm{es}}$, airway pressure and airflow waveforms. For safety reasons, the peak airway pressure was limited to a maximum of $35 \mathrm{cmH}_{2} \mathrm{O}$, regardless of achieving complete absence of inspiratory muscles during inspiratory flow. The PS ${ }_{\text {min }}$ was identified by the lowest PS without dyspnea or rapid shallow breathing (respiratory rate/tidal volume $<100 \mathrm{~min}^{-1} \mathrm{l}^{-1}$ ). Apart from the PS, all the other ventilatory variables remained constant throughout the study, as previously set by the attending physician.

The three PSV levels $\left(\mathrm{PS}_{\text {base }}, \mathrm{PS}_{\min }\right.$ and $\mathrm{PS}_{\max }$ ) were delivered in random order to each patient for $20 \mathrm{~min}$. At the end of each PS level period, five end-expiratory and endinspiratory airway occlusion maneuvers were performed. These were performed at the end of each PS period in order to avoid carry over effects originating from the previous PS level. Each occlusion maneuver lasted $3 \mathrm{~s}$ and was separated by the previous and next maneuver by at least ten noninterrupted breaths.

\subsection{Measurements and calculations}

Immediately before the beginning of the occlusion maneuvers, $\mathrm{P}_{\mathrm{es}}, \mathrm{P}_{\mathrm{aw}}$, airflow and volume curves were recorded for $5 \mathrm{~min}$ at the sampling rate of $100 \mathrm{~Hz}$ (Datex-Ohmeda S/5 Collect; Datex-Ohmeda Division, Instrumentarium Corp., Helsinki, Finland) and reconstructed from the sampled data through the R software (R Core Team, 2018, R Foundation for Statistical Computing, Vienna, Austria). The following parameters were measured on the occluded breaths: total positive end-expiratory pressure $\left(\mathrm{PEEP}_{\text {tot }}\right)$, i.e. the airway pressure recorded during end-expiratory plateau, end-expiratory plateau esophageal pressure $\left(\mathrm{P}_{\text {exp,es }}\right)$, end-inspiratory plateau airway pressure $\left(\mathrm{P}_{\text {plat,aw }}\right)$, end-inspiratory plateau esophageal pressure $\left(\mathrm{P}_{\text {plat,es }}\right)$. The minimum acceptable length for a plateau was $0.25 \mathrm{~s}$ and its adequacy was judged by visual inspection [4]. Any occlusion pressure without a clearly identifiable plateau was discarded. Auto-PEEP was calculated as the difference between PEEP $_{\text {tot }}$ and the set PEEP. Airway occlusion pressure at $100 \mathrm{~ms}\left(\mathrm{P}_{0.1}\right)$ was measured as the drop in airway pressure after $100 \mathrm{~ms}$ of an inspiratory attempt with occluded airway [13]. The onset of inspiration was identified by a fall in the esophageal pressure, the end of inspiration was identified by the last positive value of the inspiratory flow. $\mathrm{P}_{\text {musc }}$ was estimated as the maximal difference between the relaxation pressure of the chest wall $\left(\mathrm{P}_{\mathrm{cw}}\right)$ and the esophageal pressure measured during inspiration. $\mathrm{P}_{\mathrm{cw}}$ is the product of the inspired volume and the chest wall elastance $\left(\mathrm{E}_{\mathrm{cw}}\right) . \mathrm{E}_{\mathrm{cw}}$ was calculated as the ratio $\left(\mathrm{P}_{\text {plates }}-\mathrm{P}_{\text {exp,es }}\right) /$ tidal volume. Patients were categorized as 'near-passive' if $\mathrm{P}_{\text {musc }}$ was equal or lower than $1 \mathrm{cmH}_{2} \mathrm{O}$, all other patients being classified as 'active'. The Pressure-Time Product (PTP) was computed as the area between $\mathrm{P}_{\mathrm{cw}}$ and $\mathrm{P}_{\mathrm{es}}$ during inspiration multiplied by the respiratory rate (Fig. 1, left panel).

\subsection{The least square fitting method}

The pressure applied to the respiratory system during ventilation $\left(\mathrm{P}_{\text {appl }}\right)$ can be calculated at any time $t$ by the equation of motion as the sum of elastic pressure $\left(\mathrm{P}_{\mathrm{el}}\right)$ and resistive pressure $\left(\mathrm{P}_{\text {res }}\right)$ on the basal pressure $\left(\mathrm{P}_{0}\right)[5]$ :

$\mathrm{P}_{\text {appl }}(t)=\mathrm{P}_{\mathrm{el}}(t)+\mathrm{P}_{\text {res }}(t)+\mathrm{P}_{0}$.

$\mathrm{P}_{\mathrm{el}}(t)$ is the product between $\mathrm{V}(t)$, the volume at the time $t$, and $\mathrm{E}_{\mathrm{rs}} \cdot \mathrm{P}_{\mathrm{res}}(t)$ is calculated as the flow, $\mathrm{V}^{\prime}(t)$, multiplied by $\mathrm{R}_{\mathrm{rs}}$. Finally, $\mathrm{P}_{0}$ corresponds to $\mathrm{PEEP}_{\text {tot }}$. Equation 1 can be rewritten as:

$\mathrm{P}_{\mathrm{aw}}(t)=\mathrm{V}(t) \cdot \mathrm{E}_{\mathrm{rs}}+\mathrm{V} \prime(t) \cdot \mathrm{R}_{\mathrm{rs}}+\mathrm{PEEP}_{\mathrm{tot}}$.

We calculated $\mathrm{E}_{\mathrm{rs}}$ and $\mathrm{R}_{\mathrm{rs}}$ as the coefficients of $\mathrm{V}$ and $\mathrm{V}$ ', respectively, by fitting the equation of motion during $\mathrm{PS}_{\max }$. In this setting, based on previous report, we assumed that the inspiratory muscles were near totally relaxed, allowing a reliable calculation of passive respiratory mechanics $[14$, 15].

During assisted mechanical ventilation, $\mathrm{P}_{\mathrm{appl}}$ is the sum of the airway pressure $\left(\mathrm{P}_{\mathrm{aw}}\right)$, generated by the mechanical ventilator, and $\mathrm{P}_{\text {musc }}$. Equation 2 can be rewritten as:

$\mathrm{P}_{\mathrm{aw}}(t)+\mathrm{P}_{\text {musc }}(t)=\mathrm{V}(t) \cdot \mathrm{E}_{\mathrm{rs}}+\mathrm{V} \prime(t) \cdot \mathrm{R}_{\mathrm{rs}}+\mathrm{PEEP}_{\text {tot }}$.

Equation 3 can be rearranged to estimate $P_{\text {musc }}$ with the least square fitting [3] $\left(\mathrm{P}_{\text {musc,lsf }}\right)$ :

$\mathrm{P}_{\text {musc,lsf }}(t)=\mathrm{V}(t) \cdot \mathrm{E}_{\mathrm{rs}}+\mathrm{V} \prime(t) \cdot \mathrm{R}_{\mathrm{rs}}+\mathrm{PEEP}_{\text {tot }}-\mathrm{P}_{\mathrm{aw}}(t)$

$\mathrm{PTP}_{\mathrm{lsf}}$ was calculated as the area delimited by $\mathrm{P}_{\text {musc,lsf }}(t)$ (Fig. 1, right panel).

\subsection{The end-inspiratory occlusion method}

$\mathrm{P}_{\text {musc }}$ estimation with this method is also known as $\mathrm{P}_{\text {musc,index }}$ or PMI [4]. $\mathrm{P}_{\text {musc,index }}$ was calculated as the difference between $\mathrm{P}_{\text {plat,aw }}$ and the pressure applied by ventilator during the inspiratory phase:

$\mathrm{P}_{\text {musc,index }}=\mathrm{P}_{\text {plat,aw }}-(\mathrm{PS}+\mathrm{PEEP})$

where $\mathrm{P}_{\text {plat,aw }}$ is the sum of $\mathrm{P}_{\mathrm{el}}$ and $\mathrm{PEEP}_{\text {tot }}[16]$ :

$\mathrm{P}_{\text {plat }, \mathrm{aw}}=\mathrm{P}_{\mathrm{el}}+$ PEEP $_{\text {tot }}$.

Therefore, Eq. 5 can be rewritten as 
Fig. 1 Inspiratory effort assessed by esophageal pressure, least square fitting method and inspiratory occlusion method. $P_{e s}$ esophageal pressure, $P_{\text {musc }}$ inspiratory swing measured between elastic recoil pressure of chest wall and esophageal pressure, $P_{\text {musc }, l s f} \mathrm{P}_{\text {musc }}$ estimated with least square fitting method, $P_{a w}$ airway pressure, $P_{\text {musc,index }} \mathrm{P}_{\text {musc }}$ estimated with end-inspiratory occlusion method, $P S$ pressure support level, $P E E P$ positive end-expiratory pressure. a Esophageal pressure, continuous line: esophageal pressure; dashed line: elastic recoil pressure of the chest wall; dotted area: pressure-time product. b Least square fitting method, continuous line: $\mathrm{P}_{\text {musc,lsf }}$, dashed line: baseline at $0 \mathrm{cmH}_{2} \mathrm{O}$; dotted area: pressure-time product as calculated by least square fitting method. c End-inspiratory occlusion method, continuous line: airway pressure; dashed line: sum of PS and PEEP
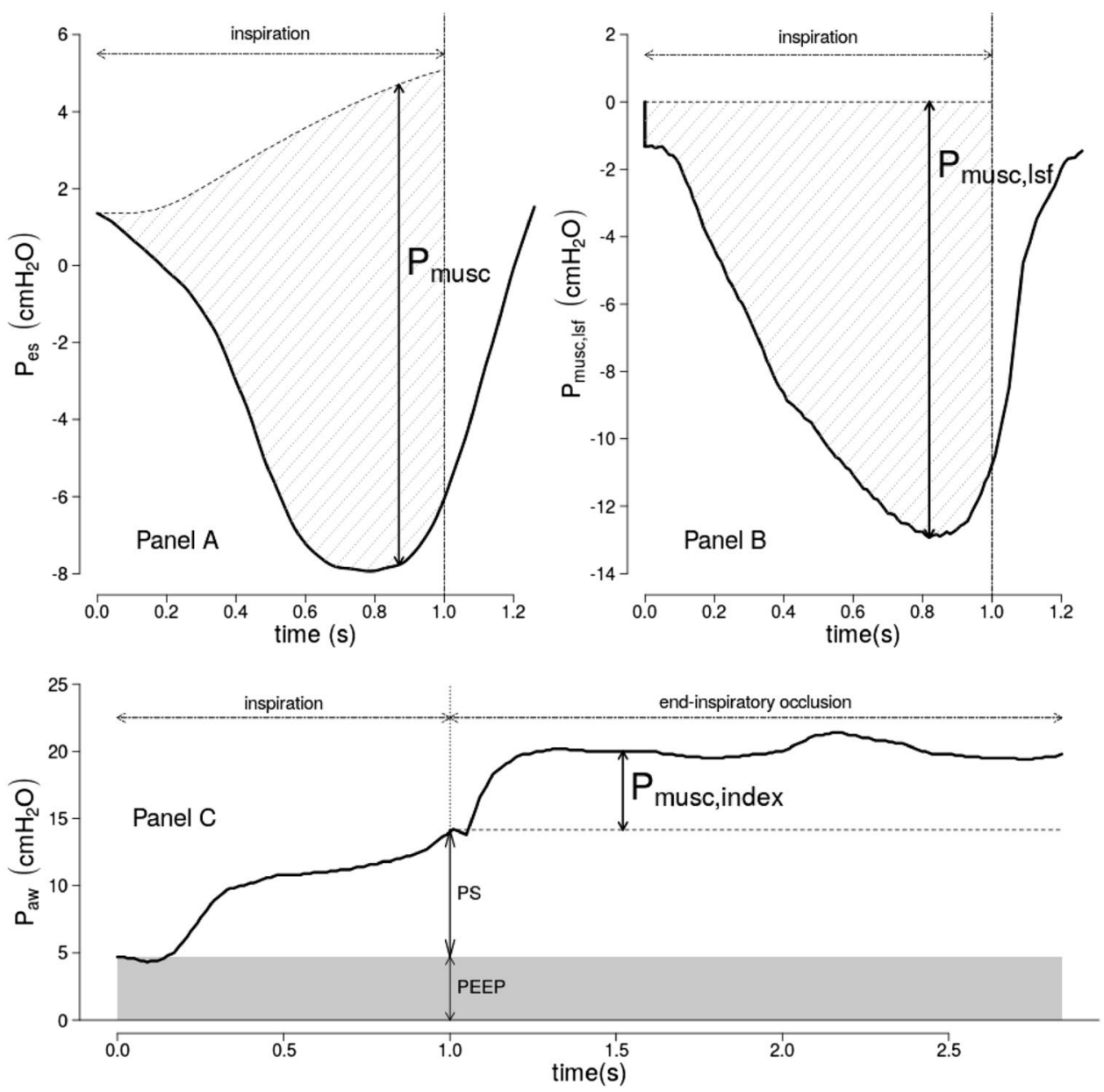

$\mathrm{P}_{\text {musc,index }}=\left(\mathrm{P}_{\mathrm{el}}+\mathrm{PEEP}_{\text {tot }}\right)-(\mathrm{PS}+\mathrm{PEEP})$

and by rearrangements

$\mathrm{P}_{\text {musc,index }}=\mathrm{P}_{\mathrm{el}}+\left(\mathrm{PEEP}_{\text {tot }}-\mathrm{PEEP}\right)-\mathrm{PS}$

Since autoPEEP is the difference between PEEP $_{\text {tot }}$ and PEEP,

$\mathrm{P}_{\text {musc,index }}=\mathrm{P}_{\mathrm{el}}+$ autoPEEP - PS.

Equation 9 makes evident that $\mathrm{P}_{\text {musc,index }}$ includes both the pressure required to generate the tidal volume and the pressure necessary to overcome auto-PEEP while the $\mathrm{P}_{\text {musc }}$ needed to overcome the resistive load remains undetected.

$\mathrm{P}_{\text {musc }}, \mathrm{P}_{\text {musc,lsf }}, \mathrm{P}_{\text {musc,index }}$, PTP and PTP $\mathrm{lsf}_{\text {sf }}$ were calculated on each breath in which the inspiratory occlusion maneuver was performed.

Each measurement was independently performed by at least 3 authors (among GN, BB, AG, EA, LP) and medians used for the analysis. " $\mathrm{P}_{\text {musc }}, \mathrm{P}_{\text {musc,lsf }}, \mathrm{P}_{\text {musc,index }}$, PTP and $\mathrm{PTP}_{\text {lsf }}$ were calculated on all breaths in which the inspiratory occlusion maneuver was performed and that were of sufficient quality to be scored by all the 3 independent scorers".

\subsection{Outcomes}

The primary outcome was the agreement between $\mathrm{P}_{\text {musc }}$ calculated through the $\mathrm{P}_{\mathrm{es}}$ method (deemed as the gold standard), $\mathrm{P}_{\text {musc,lsf }}$ and $\mathrm{P}_{\text {musc,index }}$. The secondary outcome was the accuracy of $\mathrm{P}_{\text {musc,lsf }}$ and $\mathrm{P}_{\text {musc,index }}$ to detect near-passive patients (defined as $\mathrm{P}_{\text {musc }} \leq 1 \mathrm{cmH}_{2} \mathrm{O}$, see above).

\subsection{Statistical analysis}

Data are shown as mean \pm standard deviation, median (1st3rd quartile) or frequency (percentage).

In order to detect differences among $\mathrm{P}_{\text {musc }}, \mathrm{P}_{\text {musc,lsf }}$, and $\mathrm{P}_{\text {musc,index }}$, we calculated a sample size of 18 patients obtained considering a size effect 0.4 on the primary endpoint, alpha error 0.05 , power $0.8, \mathrm{~T}$ tests family and fixed model single regression coefficient as statistical test (G*Power 3.1.9.2, Heinrich-Heine-Universität, Düsseldorf, Germany [17].

Linear mixed effects models were used to compare variables (PS level as fixed effect, patients as random effect). The methods of $\mathrm{P}_{\text {musc }}$ measurement (esophageal pressure, least square fitting, end-inspiratory pause) and their relationships 
were similarly analyzed with linear mixed effects models (method and PS levels as fixed effects, patients as random effect). Comparison among groups were analyzed with the Tukey test.

Bias and agreement were assessed by Bland-Altman analysis for repeated measures [18]. The accuracy of $P_{\text {musc,lsf }}$ and $\mathrm{P}_{\text {musc,index }}$ to detect near-passive patients was assessed by the area under the receiver operating characteristics (ROC) curve. The areas under ROC curves were compared with the DeLong test. We also calculated the positive and negative predictive values and the confidence intervals at $95 \%$ level (95\% CI), using the values that maximized the sum of sensitivity and specificity as cut-offs.

A p value lower than 0.05 was considered significant. Statistical analyses were performed with R (R Core Team, 2018. R Foundation for Statistical Computing, Vienna, Austria) with packages "Ime4" (version 1.1-17) and "multcomp" (version 1.4-8).

\section{Results}

We studied 18 consecutive patients whose baseline characteristics are shown in Table 1. Breathing pattern, respiratory drive and inspiratory effort data are shown in Table 2. By increasing the PS level, $\mathrm{P}_{\text {musc }}$ and respiratory rate decreased and tidal volume increased.

At all the three PSV levels, $\mathrm{P}_{\text {musc,lsf }}$ was not different from $\mathrm{P}_{\text {musc }}(\mathrm{p}=0.96)$, whereas $\mathrm{P}_{\text {musc,index }}$ was significantly lower than $\mathrm{P}_{\text {musc }}(\mathrm{p}<0.001)$ (Fig. 2, top panel). $\mathrm{PTP}_{1 \mathrm{sf}}$ was not different from PTP ( $p=0.92$, Fig. 2, bottom panel). The relationship between $\mathrm{P}_{\text {musc }}$ and $\mathrm{P}_{\text {musc,lsf }}$ and between

Table 1 Patients characteristics

\begin{tabular}{|c|c|}
\hline Age (years) & $71 \pm 13$ \\
\hline Female, $\mathrm{n}(\%)$ & $6(33 \%)$ \\
\hline Body mass index $\left(\mathrm{kg} \cdot \mathrm{m}^{-2}\right)$ & $26 \pm 6$ \\
\hline Days on mechanical ventilation at enrollment & $9(3-20)$ \\
\hline Patients with tracheostomy on study day, n (\%) & $7(39 \%)$ \\
\hline Length of stay in intensive care unit (days) & $21(14-32)$ \\
\hline Hospital mortality, n (\%) & $3(17 \%)$ \\
\hline Pressure support level at enrollment $\left(\mathrm{cmH}_{2} \mathrm{O}\right)$ & $10 \pm 3$ \\
\hline Positive end-expiratory pressure $\left(\mathrm{cmH}_{2} \mathrm{O}\right)$ & $6 \pm 1$ \\
\hline $\mathrm{FIO}_{2}$ & $0.37 \pm 0.08$ \\
\hline $\mathrm{pH}$ & $7.48 \pm 0.04$ \\
\hline $\mathrm{PaCO}_{2}(\mathrm{mmHg})$ & $36 \pm 7$ \\
\hline $\mathrm{PaO}_{2}(\mathrm{mmHg})$ & $92 \pm 21$ \\
\hline $\mathrm{P}_{0.1}$ at $\mathrm{PS}_{\max }\left(\mathrm{cmH}_{2} \mathrm{O}\right)$ & $1 \pm 1$ \\
\hline Elastance of the respiratory system $\left(\mathrm{cmH}_{2} \mathrm{O} \mathrm{l}^{-1}\right)$ & $19 \pm 12$ \\
\hline Resistance of the respiratory system $\left(\mathrm{cmH}_{2} \mathrm{O}^{-1} \mathrm{~s}\right)$ & $10 \pm 5$ \\
\hline
\end{tabular}

$P_{0.1}$ airway occlusion pressure at $100 \mathrm{~ms}, P S_{\max }$ maximal pressure support (see "Methods" section for details)
Table 2 Inspiratory effort and breathing pattern at the three pressure support levels

\begin{tabular}{|c|c|c|c|c|}
\hline & $P S_{\min }$ & $P S_{\text {base }}$ & $P S_{\max }$ & $p$ \\
\hline $\begin{array}{l}\text { Pressure support } \\
\left(\mathrm{cmH}_{2} \mathrm{O}\right)\end{array}$ & $4 \pm 1$ & $10 \pm 3$ & $18 \pm 5$ & $<0.001$ \\
\hline Tidal volume (ml) & $453 \pm 121$ & $544 \pm 163$ & $703 \pm 211$ & $<0.001$ \\
\hline Respiratory rate $\left(\min ^{-1}\right)$ & $27 \pm 9$ & $23 \pm 8$ & $18 \pm 6$ & $<0.001$ \\
\hline $\mathrm{P}_{\text {musc }}\left(\mathrm{cmH}_{2} \mathrm{O}\right)$ & $12 \pm 7$ & $10 \pm 8$ & $5 \pm 5$ & $<0.001$ \\
\hline $\mathrm{P}_{\text {musc,lsf }}\left(\mathrm{cmH}_{2} \mathrm{O}\right)$ & $13 \pm 7$ & $9 \pm 7$ & $5 \pm 6$ & $<0.001$ \\
\hline $\mathrm{P}_{\text {musc,index }}\left(\mathrm{cmH}_{2} \mathrm{O}\right)$ & $7 \pm 4$ & $3 \pm 5$ & $-2 \pm 3$ & $<0.001$ \\
\hline 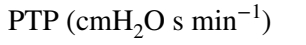 & $206 \pm 164$ & $135 \pm 128$ & $59 \pm 103$ & $<0.001$ \\
\hline $\mathrm{PTP}_{\mathrm{lsf}}\left(\mathrm{cmH}_{2} \mathrm{O} \mathrm{s} \mathrm{min} \mathrm{min}^{-1}\right)$ & $277 \pm 201$ & $167 \pm 192$ & $54 \pm 102$ & $<0.001$ \\
\hline $\mathrm{P}_{0.1}\left(\mathrm{cmH}_{2} \mathrm{O}\right)$ & $3 \pm 2$ & $3 \pm 2$ & $1 \pm 1$ & $<0.001$ \\
\hline
\end{tabular}

$P S_{\text {min }}$ minimal pressure support, $P S_{\text {base }}$ baseline pressure support, $P S_{\max }$ maximal pressure support (see "Methods" section for explanation)

$P_{\text {musc }}$ inspiratory swing measured between elastic recoil pressure of the chest wall and esophageal pressure, $P_{\text {musc,lsf }} \mathrm{P}_{\text {musc }}$ estimated with least square fitting, $P_{\text {musc index }} \mathrm{P}_{\text {musc }}$ estimated with end-inspiratory occlusion, PTP pressure-time product measured between elastic recoil pressure of the chest wall and esophageal pressure, $P T P_{l s f}$ PTP calculated with least square fitting, $P_{0.1}$ airway occlusion pressure at $100 \mathrm{~ms}$

All pairwise comparisons between the three PS levels were significant $(\mathrm{p}<0.05)$

$\mathrm{P}_{\text {musc }}$ and $\mathrm{P}_{\text {musc,index }}$ were weak although statistically significant $\left(r^{2}=0.34, p<0.001\right.$ and $r^{2}=0.19, p<0.001$ respectively).

Figure 3 shows the Bland-Altman plots assessing the agreement between $\mathrm{P}_{\text {musc }}$ and $\mathrm{P}_{\text {musc,lsf }}$ (left side) and $\mathrm{P}_{\text {musc }}$ and $\mathrm{P}_{\text {musc,index }}$ (right side). The bias between $\mathrm{P}_{\text {musc }}$ and $\mathrm{P}_{\text {musc,lsf }}$ was zero, whereas the bias between $\mathrm{P}_{\text {musc }}$ and $\mathrm{P}_{\text {musc,index }}$ was $6 \mathrm{cmH}_{2} \mathrm{O}$. Both plots show similar limits of agreement of $\pm 12 \mathrm{cmH}_{2} \mathrm{O}$ across bias.

There was a weak relationship between PTP and PTP $_{\text {lsf }}$ $\left(r^{2}=0.27, p<0.001\right)$, with a bias of $-7 \mathrm{cmH} 2 \mathrm{O} \cdot \mathrm{s} \cdot \mathrm{min}^{-1}(95 \%$ limits of agreement: from-192 to $178 \mathrm{cmH}_{2} \mathrm{O} \cdot \mathrm{s} \cdot \mathrm{min}^{-1}$ ).

$\mathrm{P}_{\text {musc,lsf }}$ and $\mathrm{P}_{\text {musc,index }}$ were moderately accurate to identify a near-passive patients, with areas under ROC curve of 0.73 (95\% CI 0.65-0.81) and 0.87 (95\% CI 0.8-0.94), respectively $(\mathrm{p}=0.01)$. Both $\mathrm{P}_{\text {musc,lsf }} \leq 4 \mathrm{cmH}_{2} \mathrm{O}$ and $\mathrm{P}_{\text {musc,index }} \leq 1 \mathrm{cmH}_{2} \mathrm{O}$ had very low positive predictive value [0.33 (95\% CI 0.23-0.45) and 0.22 (95\% CI 0.15-0.31), respectively)] but excellent negative predictive value [0.98 (95\% CI 0.94-1) and 0.96 (95\% CI 0.91-0.99), respectively)]. The sensitivity and specificity were as follow [0.89 (95\% CI 0.72-0.98) and 0.73 (95\% CI 0.66-0.79)] for $\mathrm{P}_{\text {musc,lsf }}$, respectively, and [0.86 (95\% CI 0.67-0.96) and 0.55 (95\% CI 0.47-0.62)] for $\mathrm{P}_{\text {musc,index }}$, respectively. In practical terms, one can very likely exclude that a patient is nearpassive during PSV when $\mathrm{P}_{\text {musc,lsf }}>4 \mathrm{cmH}_{2} \mathrm{O}$ or $\mathrm{P}_{\text {musc,index }}>1$ $\mathrm{cmH}_{2} \mathrm{O}$. 
Fig. 2 Measured and estimated inspiratory effort at PSmin, PSbase and Psmax. PS $_{\text {min }}$ : minimal pressure support; $\mathrm{PS}_{\text {base }}$ : baseline pressure support; $\mathrm{PS}_{\max }$ : maximal pressure support (see "Methods" section for explanation). Top: $\mathrm{P}_{\text {musc }}$ : inspiratory swing measured between elastic recoil pressure of chest wall and esophageal pressure; $\mathrm{P}_{\text {musc,lsf }}: \mathrm{P}_{\text {musc }}$ estimated with least square fitting method; $\mathrm{P}_{\text {musc,index }}: \mathrm{P}_{\text {musc }}$ estimated with end-inspiratory occlusion method. Bottom: PTP: Pressure-time product; $\mathrm{PTP}_{\text {Isf: }}$ : PTP estimated with the least square fitting method
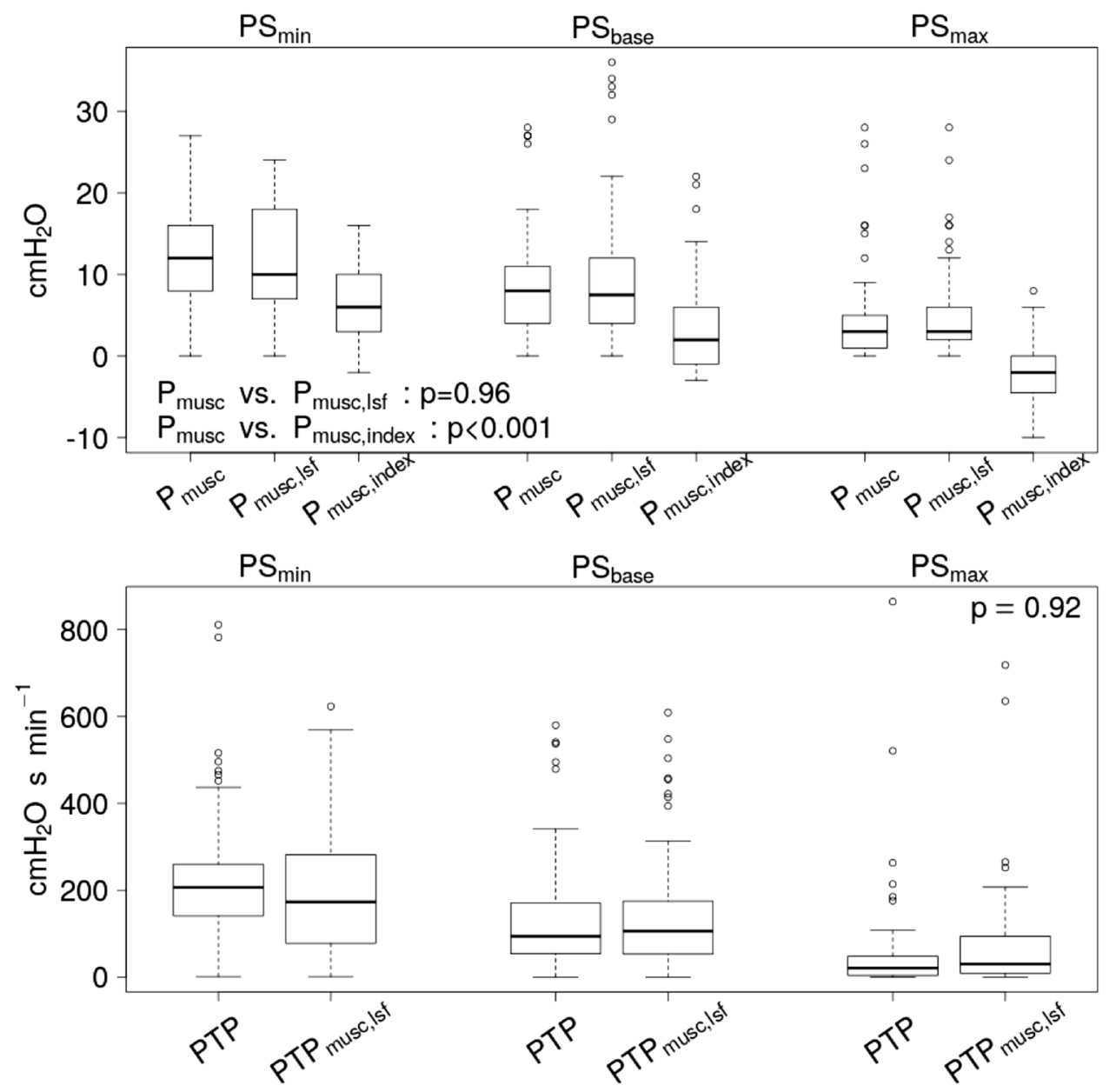

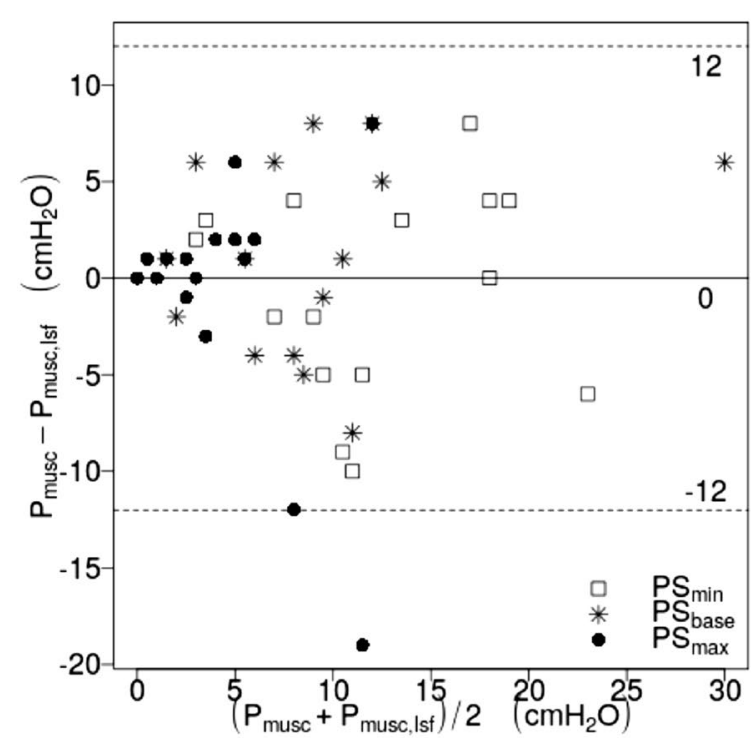

Fig. 3 Title: Bland-Altman plot for measured and calculated inspiratory effort. $P S_{\min }$ minimal pressure support, $P S_{\text {base }}$ baseline pressure support, $P S_{\max }$ maximal pressure support, $P_{\text {musc }}$ inspiratory swing of the pressure generated by respiratory muscles measured on esophageal pressure, $P_{\text {musc,lsf }}$ inspiratory swing of the pressure generated

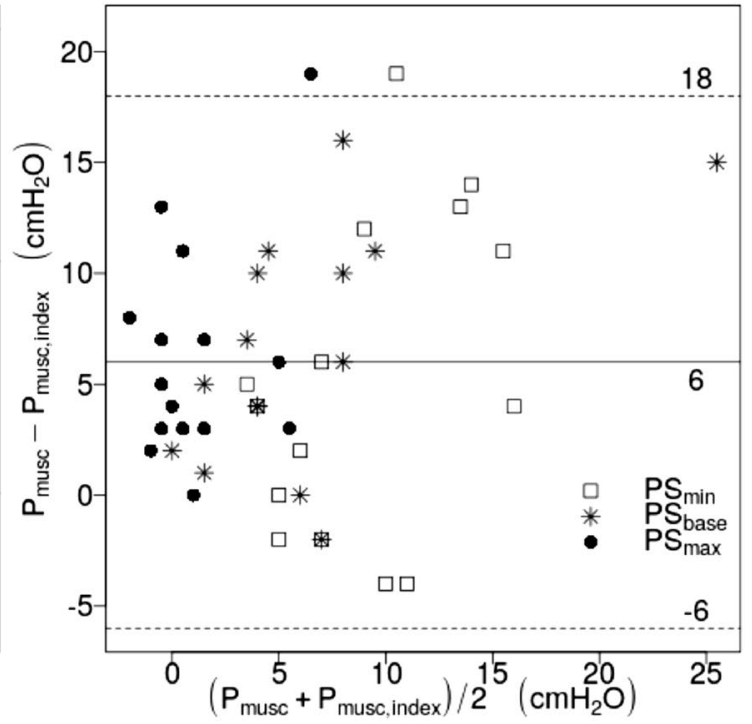

by respiratory muscles calculated with least square fitting method, $P_{\text {musc,index }}$ inspiratory pressure generated by respiratory muscles estimated with end-inspiratory occlusion method. Continuous line: bias; dashed line: $95 \%$ limits of agreement 


\section{Discussion}

Our investigation showed that the pressure developed by inspiratory muscles cannot be accurately estimated by the least square fitting or end-inspiratory occlusion as the limits of agreement between measured and estimated inspiratory effort were far above the signal size. However, both non-invasive methods of $\mathrm{P}_{\text {musc }}$ estimation tested in the present study were able to exclude that a patient was near-passive during PSV.

The least square fitting method has been proposed to estimate respiratory mechanics [14] and inspiratory effort during PSV more than 20 years ago [3] and is still in use in some mechanical ventilators. Despite average values of $\mathrm{P}_{\text {musc }}$ and $\mathrm{P}_{\text {musc,lsf }}$ were similar at different PSV levels, we found that the individual estimation of the inspiratory effort by $\mathrm{P}_{\text {musc,lsf }}$ was largely inaccurate. Theoretically there are two main factors that could impair the accuracy of the least square fitting method: flow limitation $[19,20]$ and high respiratory drive [14]. We excluded flow-limited patients from the study using the manual compression of the abdomen method, that has been shown to detect flow limitation in resting supine and seated subjects, during exercise and mechanical ventilation [7-9]. Regarding the respiratory drive, we must point out that $\mathrm{P}_{0.1}$ averaged 1 $\mathrm{cmH}_{2} \mathrm{O}$ during $\mathrm{PS}_{\max }$ (the level at which respiratory system elastance and resistance were calculated with the least square fitting method), a respiratory drive that ensures an effective near-relaxation during PSV [14]. Additionally, by re-assessing the agreement between $\mathrm{P}_{\text {musc }}$ and $\mathrm{P}_{\text {musc,lsf }}$ using only the data of the 11 patients with $\mathrm{P}_{0.1}$ equal or lower than $1 \mathrm{cmH}_{2} \mathrm{O}$, the results shown in Fig. 3 were substantially confirmed (bias $0 \mathrm{cmH}_{2} \mathrm{O}, 95 \%$ limits of agreement from -10 to $10 \mathrm{cmH}_{2} \mathrm{O}$ ). For these reasons, we believe that the failure of least square fitting to estimate $\mathrm{P}_{\text {musc }}$ cannot be explained by high respiratory drive. Iotti and coworkers previously showed that the relationship between $\mathrm{P}_{\text {musc }}$ and $\mathrm{P}_{\text {musc,lsf }}$ decreases by increasing the PS [3]. We performed a supplemental analysis by testing the relationship between $\mathrm{P}_{\text {musc }}$ and $\mathrm{P}_{\text {musc,lsf }}$ at $\mathrm{PS}_{\max }$ and, confirming the Iotti data, it was not significant $\left(r^{2}=0.002\right.$, $\mathrm{p}=0.59$ ). In summary, despite its solid theoretical basis, our data suggest that $\mathrm{P}_{\text {musc }}$ estimation with the least square fitting is not accurate during PSV.

The end-inspiratory occlusion is a "static" method, that assumes that all the applied pressure (i.e. $\mathrm{P}_{\mathrm{aw}}+\mathrm{P}_{\mathrm{musc}}$ ) is spent to generate the volume and overcome PEEP $_{\text {tot }}$, and that the applied pressure spent to generate the inspiratory airflow is negligible [4]. Accordingly, the $\mathrm{P}_{\text {musc }}$ assessed with the end-inspiratory occlusion method does not include the resistive component of work of breathing and
$\mathrm{P}_{\text {musc }}$ at end inspiration is usually lower than the maximum inspiratory deflection of $\mathrm{P}_{\text {musc }}$ during inspiration, as shown in Fig. 1 [4]. Our data confirm the systematic underestimation of $\mathrm{P}_{\text {musc }}$ by $\mathrm{P}_{\text {musc,index }}$, with an average bias of $6 \mathrm{cmH}_{2} \mathrm{O}$ (Fig. 3). The end-inspiratory occlusion method can be performed with multiple occlusions, each at a different inspiratory volume in the tidal volume range $[21,22]$. This alternative approach, requiring an external software to control the mechanical ventilator and the assessment of residual $\mathrm{P}_{\text {res }}$ at end inspiration, was able to overcome the $\mathrm{P}_{\text {musc }}$ underestimation and to reduce the $95 \%$ $\mathrm{CI}$ of agreement between $\mathrm{P}_{\text {musc }}$ and $\mathrm{P}_{\text {musc,index }}$ to -5 to 5 $\mathrm{cmH}_{2} \mathrm{O}$ [22]. Therefore, we cannot exclude that a more complex application of end-inspiratory occlusion method could yield better results.

$\mathrm{P}_{\text {musc,index }}$ and $\mathrm{P}_{\text {musc,lsf }}$ may prove to maintain a sound clinical usefulness despite their poor agreement with $\mathrm{P}_{\text {musc }}$. Diaphragm weakness is present in a high percentage of critically ill patients and is associated with increased morbidity and mortality. Indeed, a well recognized cause of diaphragm dysfunction is disuse secondary to ventilatorinduced diaphragm inactivity [1] and preserving diaphragmatic contractions during mechanical ventilation attenuates the force loss induced by inactivity [23-25]. We found that both the $\mathrm{P}_{\text {musc,index }}$ and $\mathrm{P}_{\text {musc,lsf }}$ were able to exclude a near-passive state during ventilation. Thus, $P_{\text {musc,index }}$ and $\mathrm{P}_{\text {musc,lsf }}$ may prove clinically useful if they are used to screen for patient's passivity during PSV. Since we found that the near-passive condition is very unlikely whenever $\mathrm{P}_{\text {musc,lsf }}>4 \mathrm{cmH}_{2} \mathrm{O}$ or $\mathrm{P}_{\text {musc,index }}>1 \mathrm{cmH}_{2} \mathrm{O}$, patients with $\mathrm{P}_{\text {musc,lsf }}$ below $4 \mathrm{cmH}_{2} \mathrm{O}$ or $\mathrm{P}_{\text {musc,index }}$ below $1 \mathrm{cmH}_{2} \mathrm{O}$ should be carefully assessed to exclude absent or minimal activation of inspiratory muscles, a condition often associated with auto-cycling. End-inspiratory occlusion is simpler and easier to perform at the bedside compared with the least square fitting method. Unfortunately some mechanical ventilators do not allow to perform end-inspiratory occlusions during PSV, precluding the assessment of $\mathrm{P}_{\text {plat,aw }}$ and hence to infer relevant information about patient's inspiratory effort and driving pressure [26].

One potential limitation of our study is the choice to explore the entire clinical range of the inspiratory support. This could have negatively affected the agreement between $\mathrm{P}_{\text {musc }}$ and its non-invasive estimates; however, we considered this pragmatic design a strength rather than a limitation, as it sought to validate the least square fitting and the end-inspiratory occlusion methods in a wide range of clinical circumstances. We cannot exclude, however, that different PSV levels than the ones tested in our study would have improved the performance of the non-invasive $\mathrm{P}_{\text {musc }}$ estimation method. 


\section{Conclusions}

In conclusion, our investigation showed that the inspiratory effort during PSV could not be accurately estimated by the least square fitting or end-inspiratory occlusion method. These non-invasive approaches, however, proved valid to screen patients at risk for absent or minimal respiratory muscles activation to prevent the ventilator-induced diaphragmatic dysfunction.

Author contributions $\mathrm{GN}, \mathrm{AR}$ and $\mathrm{AB}$ contributed to the conception and design of the study; GN, BB, AG, EA, LP, GC, VL contributed to the acquisition of data; GN and LP contributed to the analysis of the data; GN, LP and Salvatore Grasso drafted the manuscript; Nicola Latronico and Massimo Antonelli revised the manuscript; all authors contributed to the interpretation of the data, critically revised the manuscript and approved the final version to be submitted.

Funding The study was supported by the departemental funding of the Department of Intensive Care and Anesthesiology, Fondazione Poliambulanza, Brescia, Italy.

Data availability The datasets used and/or analysed during the current study are available from the corresponding author on reasonable request.

\section{Compliance with ethical standards}

Conflict of interest The authors declare that they have no competing interests.

Ethical approval The protocol was approved by the local ethical committee (Comitato Etico Provinciale di Brescia, approval number NP2245).

Informed consent Written informed consent was obtained from the patient. In case of altered consciousness, the Ethics Committees waived the requirement for consent, as in Italy relatives are not regarded as legal representatives of the patient in the absence of a formal designation. Written informed consent was requested from all surviving patients as soon as they regained their mental competency.

\section{References}

1. Supinski GS, Morris PE, Dhar S, et al. Diaphragm dysfunction in critical illness. Chest. 2018;153:1040-51.

2. American Thoracic Society/European Respiratory Society. ATS/ ERS statement on respiratory muscle testing. Am J Respir Crit Care Med. 2002;166:518-624.

3. Iotti GA, Braschi A, Brunner JX, et al. Noninvasive evaluation of instantaneous total mechanical activity of the respiratory muscles during pressure support ventilation. Chest. 1995;108:208-15.

4. Foti G, Cereda M, Banfi G, et al. End-inspiratory airway occlusion: a method to assess the pressure developed by inspiratory muscles in patients with acute lung injury undergoing pressure support. Am J Respir Crit Care Med. 1997;156:1210-6.
5. Otis AB, Fenn WO, Rahn H. Mechanics of breathing in man. J Appl Physiol. 1950;2:592-607.

6. Boles J-M, Bion J, Connors A, et al. Weaning from mechanical ventilation. Eur Respir J. 2007;29:1033-56.

7. Ninane V, Leduc D, Kafi SA, et al. Detection of expiratory flow limitation by manual compression of the abdominal wall. Am J Respir Crit Care Med. 2001;163:1326-30.

8. Abdel Kafi S, Serste T, Leduc D, et al. Expiratory flow limitation during exercise in COPD: detection by manual compression of the abdominal wall. Eur Respir J. 2002;19:919-27.

9. Lemyze M, Favory R, Alves I, et al. Manual compression of the abdomen to assess expiratory flow limitation during mechanical ventilation. J Crit Care. 2012;27:37-44.

10. Baydur A, Behrakis PK, Zin WA, et al. A simple method for assessing the validity of the esophageal balloon technique. Am Rev Respir Dis. 1982;126:788-91.

11. Mauri T, Yoshida T, Bellani G, et al. Esophageal and transpulmonary pressure in the clinical setting: meaning, usefulness and perspectives. Intensive Care Med. 2016;42:1360-73.

12. Mojoli F, Iotti GA, Torriglia F, et al. In vivo calibration of esophageal pressure in the mechanically ventilated patient makes measurements reliable. Crit Care. 2016;20:98.

13. Conti G, Antonelli M, Arzano S, et al. Equipment review. Measurement of occlusion pressures in critically ill patients. Crit Care. 1997;1:89.

14. Iotti GA, Braschi A, Brunner JX, et al. Respiratory mechanics by least squares fitting in mechanically ventilated patients: applications during paralysis and during pressure support ventilation. Intensive Care Med. 1996;21:406-13.

15. Berger KI, Sorkin IB, Norman RG, et al. Mechanism of relief of tachypnea during pressure support ventilation. Chest. 1996;109:1320-7.

16. Rossi A, Gottfried SB, Zocchi L, et al. Measurement of static compliance of the total respiratory system in patients with acute respiratory failure during mechanical ventilation. Am Rev Respir Dis. 1985;131:672-7.

17. Faul F, Erdfelder E, Lang A-G, et al. G*Power 3: a flexible statistical power analysis program for the social, behavioral, and biomedical sciences. Behav Res Methods. 2007;39:175-91.

18. Bland JM, Altman DG. Agreement between methods of measurement with multiple observations per individual. J Biopharm Stat. 2007; 17:571-82.

19. Peslin R, da Silva J, Chabot F, et al. Respiratory mechanics studied by multiple linear regression in unsedated ventilated patients. Eur Respir J. 1992;5:871-8.

20. Volta CA, Marangoni E, Alvisi V, et al. Respiratory mechanics by least squares fitting in mechanically ventilated patients: application on flow-limited COPD patients. Intensive Care Med. 2002;28:48-52.

21. Pesenti A, Pelosi P, Foti G, et al. An interrupter technique for measuring respiratory mechanics and the pressure generated by respiratory muscles during partial ventilatory support. Chest. 1992;102:918-23.

22. Bellani G, Patroniti N, Weismann D, et al. Measurement of pressure-time product during spontaneous assisted breathing by rapid interrupter technique. Anesthesiology. 2007;106:484-90.

23. Sassoon CSH, Zhu E, Caiozzo VJ. Assist-control mechanical ventilation attenuates ventilator-induced diaphragmatic dysfunction. Am J Respir Crit Care Med. 2004;170:626-32.

24. Futier E, Constantin J-M, Combaret L, et al. Pressure support ventilation attenuates ventilator-induced protein modifications in the diaphragm. Crit Care. 2008;12:R116.

25. Dimussi R, Spadaro S, Mirabella L, et al. Impact of prolonged assisted ventilation on diaphragmatic efficiency: NAVA versus PSV. Crit Care. 2015;20:1. 
26. Bellani G, Grassi A, Sosio S, et al. Plateau and driving pressure in the presence of spontaneous breathing. Intensive Care Med. 2019;45:97-8.
Publisher's Note Springer Nature remains neutral with regard to jurisdictional claims in published maps and institutional affiliations.

\section{Affiliations}

\section{Giuseppe Natalini ${ }^{1} \cdot$ Barbara Buizza $^{2} \cdot$ Anna Granato ${ }^{1,3} \cdot$ Eros Aniballi $^{1,3} \cdot$ Luigi Pisani $^{1,5} \cdot$ Gianni Ciabatti $^{7}$ (1) Valeria Lippolis ${ }^{1,4} \cdot$ Antonio Rosano $^{1} \cdot$ Nicola Latronico $^{2,8} \cdot$ Salvatore Grasso ${ }^{4}$ - Massimo Antonelli, ${ }^{3,6}$. Achille Bernardini ${ }^{1}$}

1 Department of Intensive Care and Anesthesiology, Fondazione Poliambulanza, Brescia, Italy

2 Department of Intensive Care and Anesthesiology, University of Brescia, Brescia, Italy

3 Department of Intensive Care and Anesthesiology, Fondazione Policlinico Universitario A.Gemelli IRCCS, Roma, Italy

4 Department of Emergency and Organ Transplants (DETO), Anesthesiology and Intensive Care, Università Degli Studi Di Bari "Aldo Moro", Bari, Italy
5 Department of Intensive Care, Amsterdam University Medical Centers - Location AMC, Amsterdam, Netherlands

6 Catholic University of Sacred Heart, Roma, Italy

7 Department of Anesthesiology and Intensive Care, Neurointensive Care Unit, Azienda Ospedaliera Universitaria Careggi, Firenze, Italy

8 Department of Medical and Surgical Specialties, Radiological Sciences and Public Health, University of Brescia, Brescia, Italy 